\title{
Bio-inspired Recyclable Carbon Interface for Solar Steam Generation
}

\author{
Lei Shi ${ }^{1,2}$, Xinzhi Wang $^{1}$, Yanwei $\mathrm{Hu}^{1}$, Yurong $\mathrm{He}^{1^{*}}$, Yuying Yan $^{2,3}$ \\ 1. School of Energy Science and Engineering, Harbin Institute of Technology, Harbin 150001, China \\ 2. Fluids \& Thermal Engineering Research Group, Faculty of Engineering, University of Nottingham, NG7 2RD, UK \\ 3. Research Centre for Fluids and Thermal Engineering, University of Nottingham Ningbo China, Ningbo 315100, China
}

\begin{abstract}
Solar power, as one of renewable energy, holds potential application for producing steam which relies on high-temperature liquid by traditional methods. Herein, steam was generated by a bio-inspired strategy derived from the plants transpiration using a Printed Recyclable Carbon Membrane (PRCM). The membrane structure facilitated the concentration of carbon particles for the photoreaction and the heat generation for water evaporation, thereby improving the photo-thermal conversion efficiency. The PRCM achieved the best steady evaporation efficiency of $51.9 \%$, which was 5.6 times higher than the value for water and recycling tests were demonstrated. The carbon particles were separated from the water under the magnetism action, a convenient approach that avoided secondary pollution resulting from the disintegration of the PRCM. Rapid preparation, low cost, and reusability of the printed carbon membrane allow for photo-thermal applications such as solar steam generation and seawater desalination.
\end{abstract}

Keywords: solar steam generation, photo-thermal conversion, bionic heat transfer process, magnetic control Copyright $\odot$ The author(s) 2020.

\section{Introduction}

Solar energy becomes one of the most remarkable natural resources because of its abundance and the lack of pollutants that are generated during its use $\mathrm{e}^{[1,2]}$. The development of neoteric solar power system with low cost, high efficiency and excellent stability is a priority in addressing the energy crisis ${ }^{[3,4]}$. Recently, many investigations have been paid to solar evaporation due to its considerable conversion efficiency for generating steam $^{[5-8]}$. Efficiently vapor production is a key to water treatment, large-scale solar power concentration, and seawater desalination ${ }^{[9]}$. Many researches improve the efficiency of photothermal conversion by optimizing the structure of solar evaporators. For instance, at the bottom of the solar cell, black foam is used to increase the evaporation rate by $10 \%{ }^{[10]}$. Taylor et al. ${ }^{[11]}$ developed a small-scale nanofluid container that is more efficient than a surface-based collector.

To the best of our knowledge, a new method for accelerating solar evaporation was demonstrated by Zeng et al. ${ }^{[12]}$ using the carbonization of poly decorated with magnetic particles. A multilayered structure was established for solar steam generation by limiting the production of thermal energy to a localized hot spot ${ }^{[13]}$. Since then, many studies have been published on solar evaporation using various new structures and materials, especially nanomaterials ${ }^{[14-17]}$. This new technology can be used for industrial applications such as brine management, solar desalination and wastewater treatment and represents one of the most efficient methods for using solar energy with a high absorption ability in the solar spectrum ${ }^{[18,19]}$. In order to use nanofluids to produce steam, solar energy is converted into the heat of the nanofluid and the latent heat of vaporization ${ }^{[20]}$. High-concentration nanofluids were used to achieve a high evaporation efficiency. Low-concentration nanofluids are mainly applied for heat collection because of the enhanced photo-absorption resulting from the dispersed nanoparticles ${ }^{[7,21]}$.

Some studies have demonstrated that a superior evaporation efficiency could be obtained by localized heating at air-water interface, whose material is the key for solar evaporation systems ${ }^{[22]}$. Thus, many surface materials of various structures especially biological systems have been developed to promote the evaporation

\footnotetext{
*Corresponding author: Yurong $\mathrm{He}$

E-mail: rong@hit.edu.cn
} 
efficiency ${ }^{[23]}$. In the transpiration of plant hydrological cycle systems, porous structures and the localized heating are two important parts to efficient vapor generation $^{[24]}$. Based on this, a bio-inspired surface was established using high temperature of plasmonic heated localization, which resulted in fast and efficient evaporation $^{[22]}$. Liu et al. ${ }^{[16]}$ reported that a multifunctional film consisting of a $\mathrm{TiO}_{2}$ nanoparticles layer and an Au nanoparticles layer produced clean water by steam generation and photocatalytic degradation using simulated sunlight illumination, which is significant for controlling organic pollution in water. These devices had excellent ability for solar light absorption. Noble metal nanoparticles such as gold and silver frequently agglomerate after long-time solar irradiation, which weakens the optical absorption and subsequent local heating ${ }^{[25]}$. Hence, carbon-based materials such as graphene and carbon nanotubes are recently novel localized heating surfaces for photo-thermal conversion due to their high solar absorption ability. Nevertheless, the synthesis processes of graphene and carbon nanotubes are often expensive and difficult, which involves many complex chemical processes. In addition, the materials require rapid preparation and stabilization for industrial applications. Moreover, nanoparticles used in nanofluids or membranes should be recoverable after multiple evaporation processes to avoid secondary pollution ${ }^{[26]}$.

In this work, a bio-inspired recyclable carbon interface based on highly efficient laser printing technology was prepared through a quick and low-cost method for solar steam generation. The optical properties of the Printed Recyclable Carbon Membranes (PRCMs) were optimized by tuning particles concentration on the PRCMs. Firstly, different carbon membranes were quickly prepared by a printing process and their structures, morphologies and properties were investigated. Subsequently, the effects of carbon particle concentration and illumination intensity on evaporation efficiency and rate were systemically researched. We also compared particles separation phenomena under different magnetic fields to determine the recovery speed and efficiency of the carbon particles. This study advances the bio-inspired method for interface-heated photo-thermal conversion based on PRCMs, which represents an economical method using recyclable materials for solar applications.

\section{Experimental}

\subsection{Preparation and characterization of bio-inspired PRCMs}

The interface steam generation method is inspired by plant transpiration process (Fig. 1): solar radiation is absorbed by plant leaves and converted into thermal energy, which heated water inside the leaves and converted into vapor released rapidly from the leave stomata $^{[27,28]}$. The water at the interface is heated and evaporated while the volume liquid temperature remains low. The energy source generated by solar steam is solar radiation. Local heating of the liquid on the evaporation surface is the key to effective evaporation. Hence, it is necessary to introduce the preparation method of locally heated surface material. The imaging drum is charged with static electricity to attract toner by laser printing technology, which promotes digitized graphics quickly projected on a photosensitive surface. The blank film (Thai King Co., Ltd.) is heated by the laser beam resulting in the location to produce electronic discharge phenomenon, and the carbon particles is melted through the charge adsorption in the film due to the electrostatic effect to complete the printing process of thermal imaging. Use different shades to control the quality of carbon particles within different masses on the film. Five films of different carbon densities $\left(2.89 \mathrm{~g} \cdot \mathrm{m}^{-2}, 4.33 \mathrm{~g} \cdot \mathrm{m}^{-2}\right.$, $5.77 \mathrm{~g} \cdot \mathrm{m}^{-2}, 7.22 \mathrm{~g} \cdot \mathrm{m}^{-2}$ and $10.11 \mathrm{~g} \cdot \mathrm{m}^{-2}$ ) within $4 \mathrm{~cm}$ diameter were prepared. Scanning Electron Microscopy (SEM), X-ray diffractometer analysis (XRD), and UV-Vis-Near-infrared spectroscopy were performed by SUPRA 55 SAPPHIRE (ZEISS, German), D8-Advance AXS (Bruker, Germany) and at an accelerating voltage

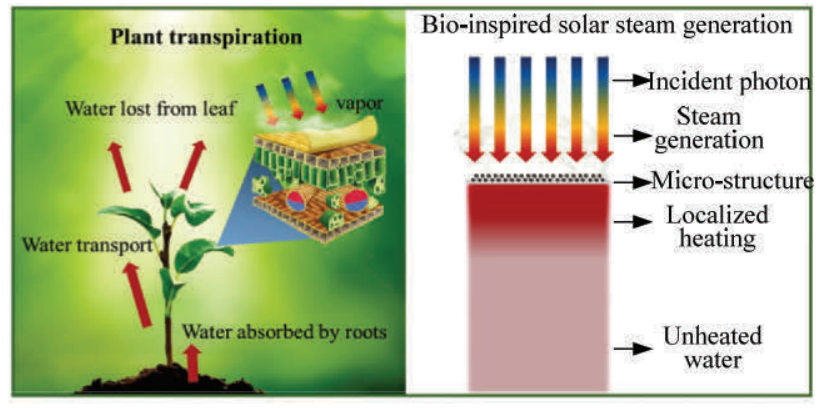

Fig. 1 Bio-inspired solar steam generation from the transpiration of plant. 


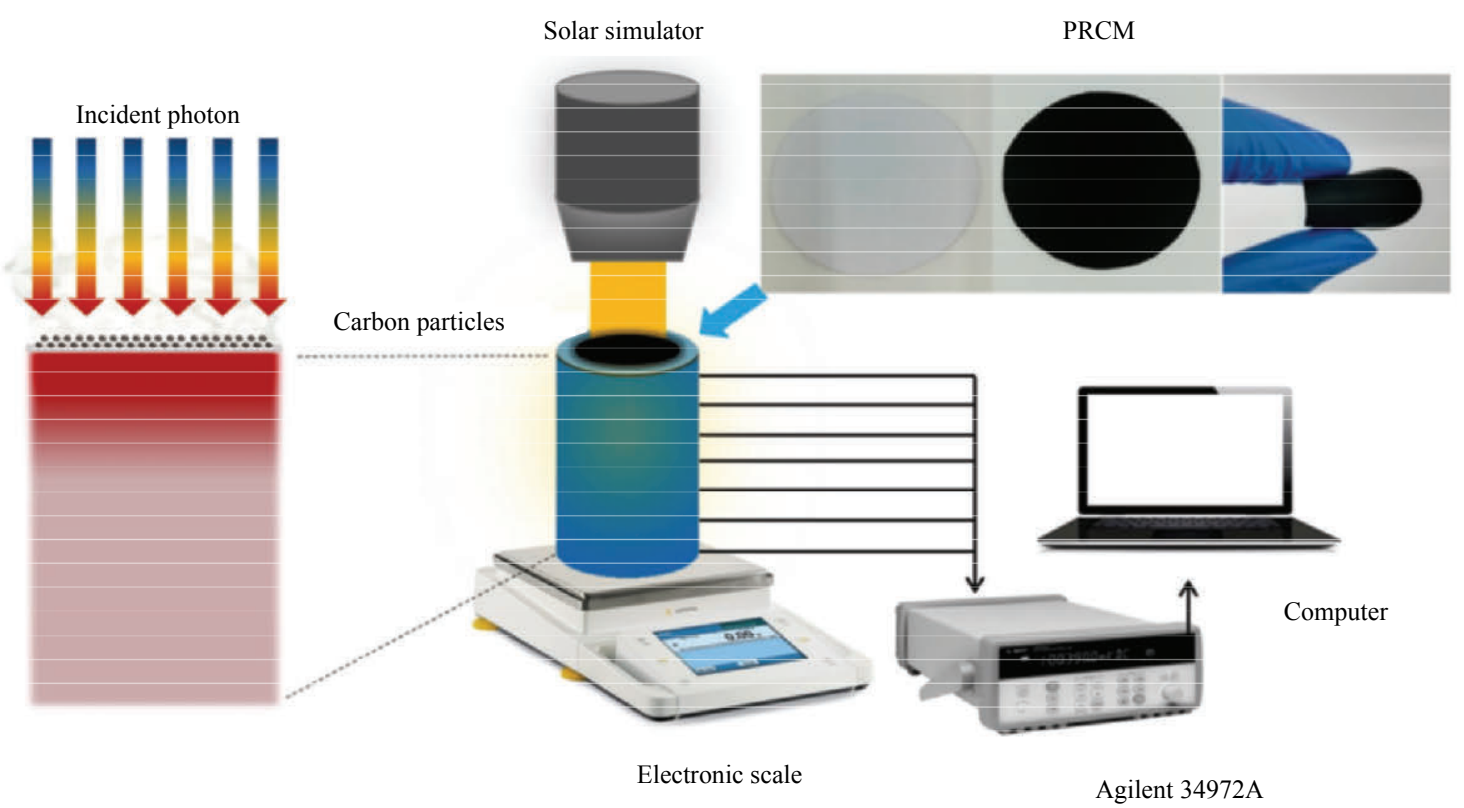

Fig. 2 Schematic of the experimental facility for solar steam generation.

of $20 \mathrm{kV}$ (SUPRA 55 SAPPHIRE) and Lambda 950 (PerkinElmer, US), separately.

\subsection{Solar steam generation experiments}

The experimental facility of solar steam generation is showed in Fig. 2. The solar rays generated by the solar simulator (HXF300, CeauLight, China) hit the floating PRCM surface vertically. A data acquisition system (34972A, Agilent Technology, CA, US) and a capacity receiver were used in the experiment. The designed test chamber consists of an acrylic beaker with an inner diameter of $40 \mathrm{~mm}$ and a height of $80 \mathrm{~mm}$. Seven $t$-type thermocouples (TT-T-40-SLE, Omega, US) were inserted into the center of the cavity, and the temperature of the nanofluid at different heights was measured uniformly. The bottom and sides of the test chamber are covered with insulation material to reduce heat loss during the test.

\subsection{Separation experiments of recoverable particles}

Considering the damage to the PRCM caused by unstable factors such as physical friction and chemical corrosion during actual applications, it is inevitable that some carbon particles from the PRCM may fall into the water. Printed carbon particles could be recoverable after solar steam generation processes ${ }^{[29]}$. The magnetic se- paration experiment of carbon suspension in this work was conducted using two methods (surface magnetic field and homogeneous magnetic field) to simulate actual and complex conditions. The magnetic separation experiment was conducted in an acrylic beaker with an inner diameter of $18 \mathrm{~mm}$ and a height of $40 \mathrm{~mm}$ (Fig. 3a). A 1548-Gs NdFeB magnet and a homogeneous magnetism $(100 \mathrm{mT})$ were used separately (Fig. $3 \mathrm{~b})$. The magnetism can be adjusted by changing the current and the distance between the poles. The magnetic separation was monitored under different magnetism strengths ( $25 \mathrm{mT}, 50 \mathrm{mT}, 100 \mathrm{mT}$ and $200 \mathrm{mT}$ ) which could be measured by magnetometer.

\section{Results and discussion}

\subsection{Characterization of magnetic carbon particles and PRCMs}

From Fig. 4a, the SEM images of the magnetic carbon particles indicate that the carbon particles used for the preparation of the PRCM have an average diameter ranging from $5 \mu \mathrm{m}$ to $7 \mu \mathrm{m}$. The XRD patterns of the magnetic carbon particles show the characteristic peaks of magnetite (Fig. 4c); the different diffraction peaks correspond well to the (1 111$),\left(\begin{array}{lll}2 & 2 & 0\end{array}\right),\left(\begin{array}{lll}3 & 1 & 1\end{array}\right)$,

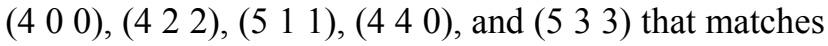
the standard pattern of magnetite (JCPDS No. 89-0691). 
(a)

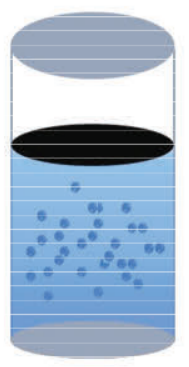

Surface magnetic field

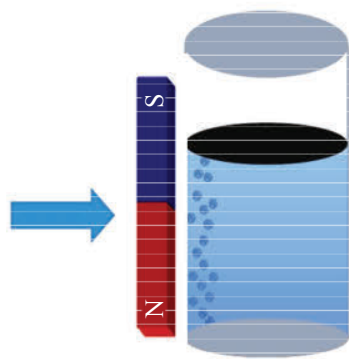

(b)

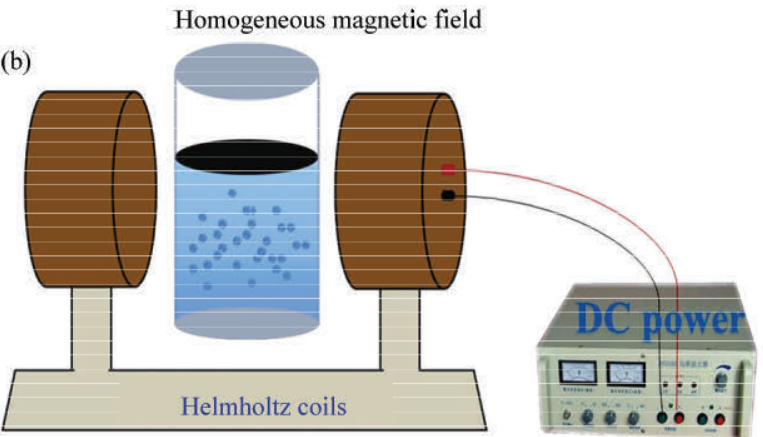

Fig. 3 Schematic of the magnetic separation. (a) Surface magnetic field; (b) homogeneous magnetic field.

(a)
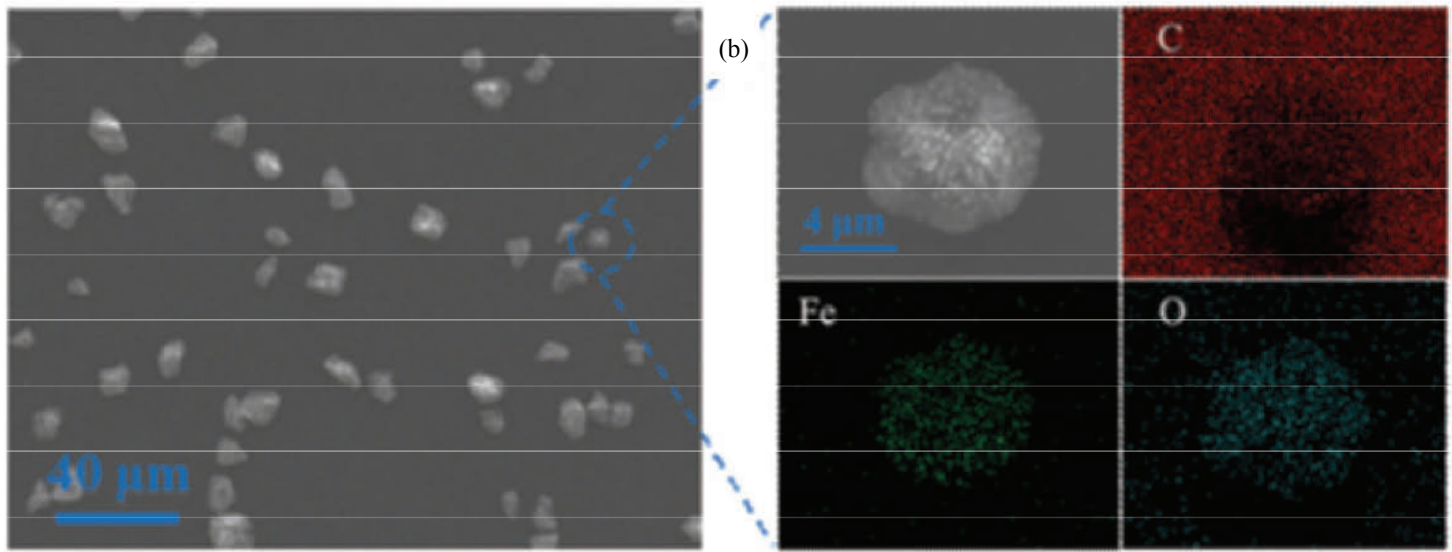

(c)

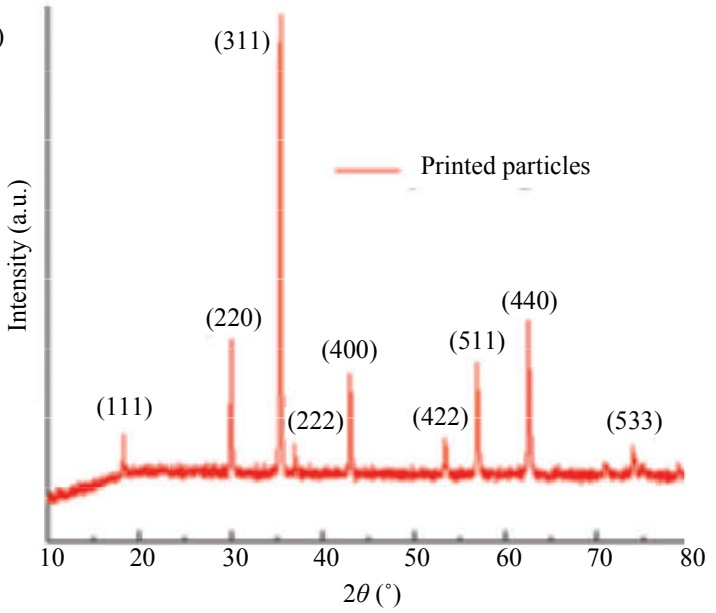

(d)

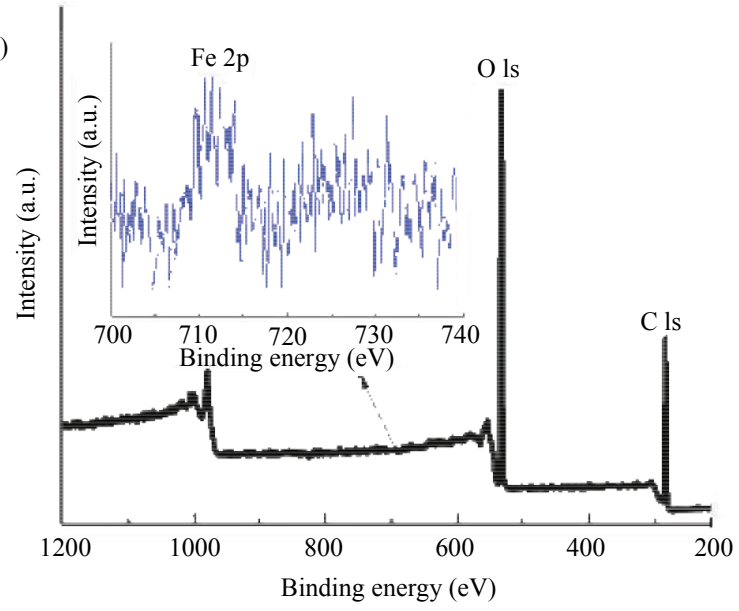

Fig. 4 Structural characterization of magnetic carbon particles. (a) SEM microstructure; (b) EDS mapping analysis; (c) XRD patterns; (d) XPS spectra.

The distribution of $\mathrm{C}, \mathrm{O}$, and $\mathrm{Fe}$ of the PRCM in the elements mapping (Fig. 4b) is verified by the X-ray photoelectron spectrometry spectra (Fig. 4d) at $282.6 \mathrm{eV}$, $528.9 \mathrm{eV}$, and $709.8 \mathrm{eV}$, which are resulting from $\mathrm{C} 1 \mathrm{~s}$, $\mathrm{O} 1 \mathrm{~s}$, and $\mathrm{Fe} 2 \mathrm{p}$. These results indicate that the magnetic carbon nanoparticles are composed by crystalline $\mathrm{Fe}_{3} \mathrm{O}_{4}$ and amorphous carbon. The SEM images of the PRCM (Fig. 5a) indicate the different printing patterns change the concentration of the magnetic carbon particles on the membrane. Contact angle measurements (Fig. 5b) using a water droplet on the surface of the paper membrane and PRCM indicate that the contact angles change from 
(a)

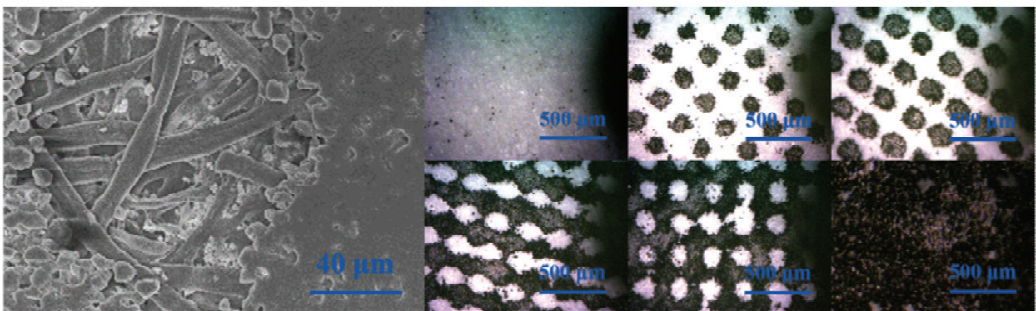

(b) $83^{\circ} \quad 107^{\circ}$

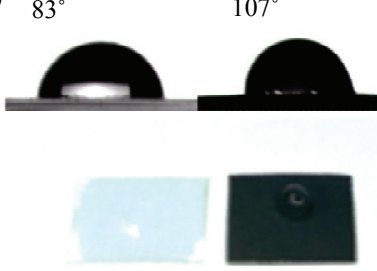

(c)
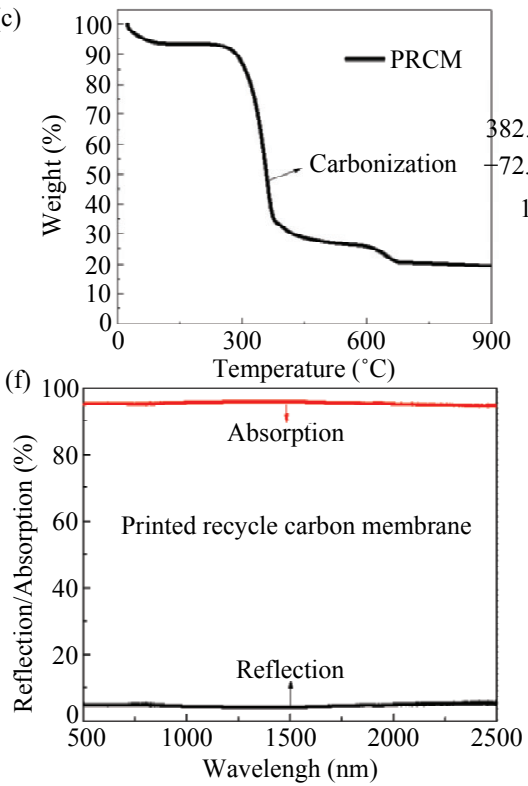

(d)
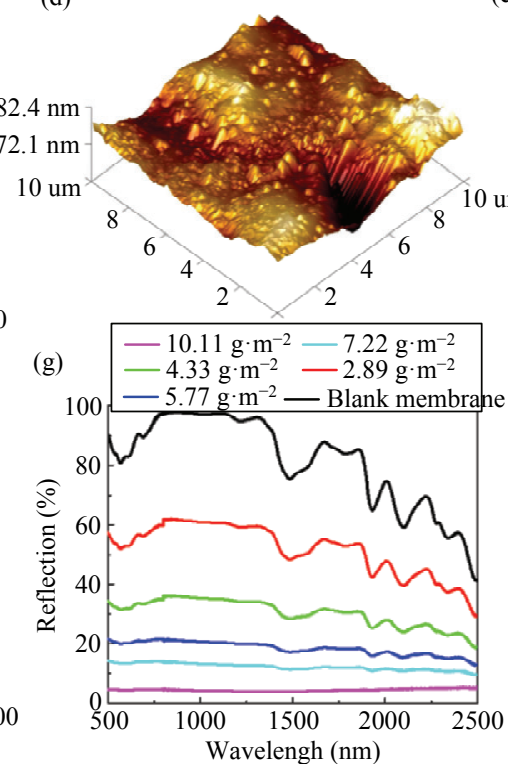

(e)

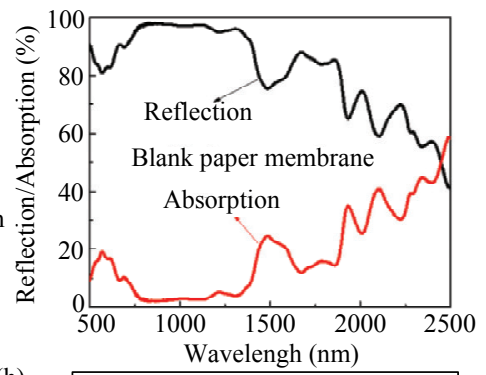

(h)

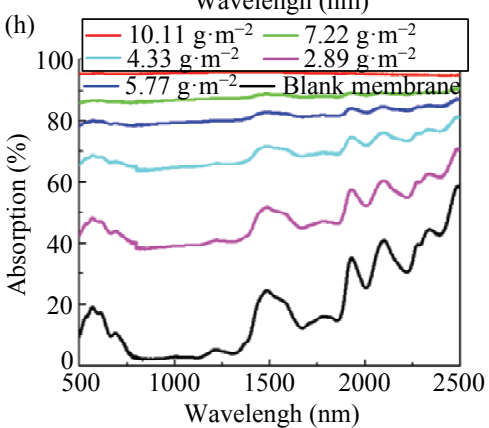

Fig. 5 Structural characterization of PRCM. (a) Microstructure by SEM and AFM; (b) contact angles for filter membranes and PRCMs; (c) TGA measurement under $\mathrm{N}_{2}$ protection; (d) 3D AFM images; the absorption and reflection of (e) filter membranes and (f) PRCM; (g) the reflection and $(\mathrm{h})$ absorption of different mass concentration of PRCM.

$83^{\circ}$ to $107^{\circ}$, demonstrating that the PRCM changes from hydrophilic to hydrophobic as a result of the printed carbon particles that contributed to the PRCM floating on the surface. A thermogravimetric analysis (TGA) was used to analyze the contents of the components of PRCMs and their transformation processes (Fig. 5c). The carbonation of cellulose starts at around $300{ }^{\circ} \mathrm{C}$ and the ends at $800{ }^{\circ} \mathrm{C}-900{ }^{\circ} \mathrm{C}$ in nitrogen. The carbon yield is around $19 \%$. Owing to the addition of granules, the PRCM exhibits micro-scale surface roughness from the atomic force microscope (Fig. 5d). The rough surface results in multiple-scattering effects of the incident sunlight that enhances the solar absorption ability of carbon particles. As for the reflection spectra and total absorption, the blank membrane exhibits low absorption and high reflection in the wavelength range (Fig. 5e). PRCM is just the opposite, the low reflection and high absorption $(95 \%$ in the range of $500 \mathrm{~nm}-2500 \mathrm{~nm})$ exhibited by the PRCM indicates that most sunlight is absorbed in this wavelength range (Fig. 5f). As showed in Figs. 5g and 5h, the light reflection of the PRCM with different mass concentrations of carbon particles decreases gradually with increasing amounts of the deposited carbon particles within wavelength range of $400 \mathrm{~nm}-2500 \mathrm{~nm}$. In addition, the light absorption of the PRCM increases gradually with increasing concentrations of the carbon particles and it remains at a high level.

\subsection{Solar steam generation enhancement with PRCM}

Because both the carbon particle mass concentration of the PRCM and the solar illumination intensity had crucial influence on the steam generation performance, experiments within a constant 4 suns intensities were conducted at different carbon particle concentrations $\left(2.89 \mathrm{~g} \cdot \mathrm{m}^{-2}, 4.33 \mathrm{~g} \cdot \mathrm{m}^{-2}, 5.77 \mathrm{~g} \cdot \mathrm{m}^{-2}, 7.22 \mathrm{~g} \cdot \mathrm{m}^{-2}\right.$ 
and $\left.10.11 \mathrm{~g} \cdot \mathrm{m}^{-2}\right)$. Then, the effect of solar light intensity was researched after determining the optimal carbon particle concentration. The experiments of solar steam generation within a constant carbon concentration $\left(7.22 \mathrm{~g} \cdot \mathrm{m}^{-2}\right)$ were conducted under different solar illuminations ( 1 sun, 2 suns, 3 suns, 4 suns and 8 suns). The vapor generation efficiency $(\eta)$ was used during stable period $(30 \mathrm{~min}-60 \mathrm{~min})$. It was defined as ${ }^{[13]}$.

$$
\eta=\frac{h_{\mathrm{lv}} \sum_{i=30}^{60}\left(m_{i+1}-m_{i}\right)}{q S t},
$$

where $h_{\mathrm{lv}}$ is the phase-change enthalpy $\left(\mathrm{kJ} \cdot \mathrm{g}^{-1}\right), q$ is the power density of light illumination $\left(\mathrm{kW} \cdot \mathrm{m}^{-2}\right)$, and $m_{i+1}-m_{i}$ denotes the evaporation flux of water $\left(\mathrm{kg} \cdot \mathrm{min}^{-1}\right)$, $t$ is the evaporation time (min), $A$ is the solar radiation area. To quantify the photo-thermal conversion performance of such devices, $\eta_{\mathrm{t}}$ was defined the thermal efficiency that represents the percentage of total heat transferred from solar energy to bulk water ${ }^{[23]}$ :

$$
\eta_{\mathrm{t}}=\frac{m_{\mathrm{v}} c_{\mathrm{p}, \mathrm{l}} \Delta T+m_{\mathrm{w}} h_{\mathrm{v}}}{q S t},
$$
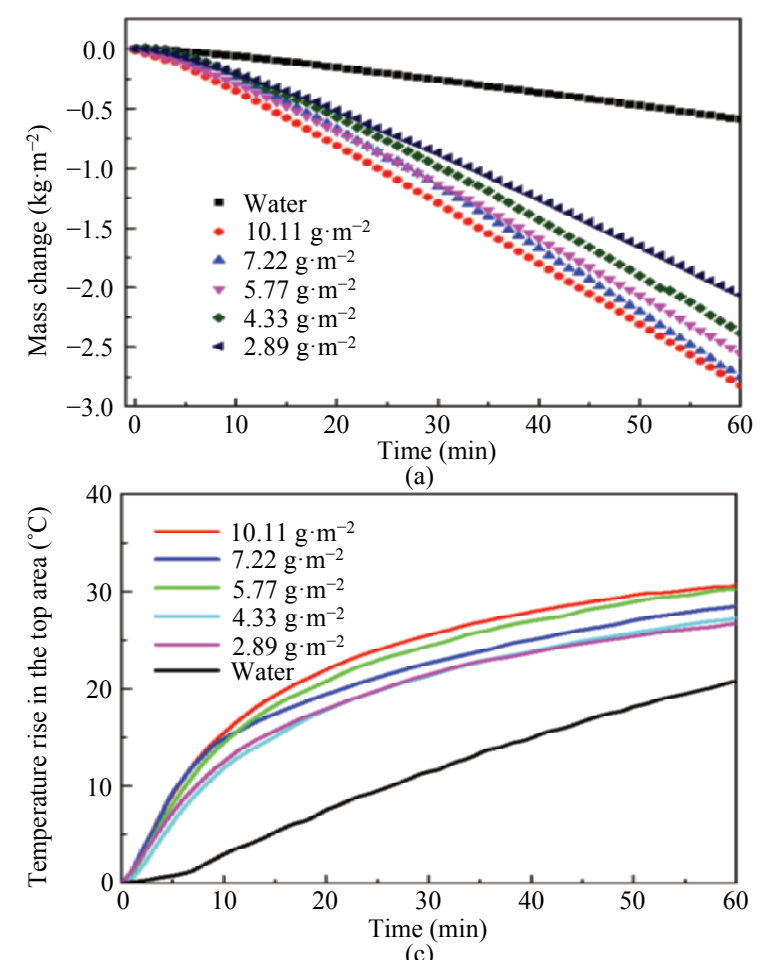

(c) where $m_{\mathrm{v}}$ is the mass of the bulk water $(\mathrm{kg}), m_{\mathrm{w}}$ is the total amount of evaporated water $(\mathrm{kg}), c_{\mathrm{p}, 1}$ is the specific heat of water at standard atmospheric pressure $\left(4.2 \mathrm{~kJ} \cdot \mathrm{kg}^{-1} \cdot \mathrm{K}^{-1}\right)$, and $\Delta T$ is the rise in the bulk water temperature.

3.2.1 Effect of carbon particles concentration on vapor generation performance

Fig. 6a shows the mass change of the bulk water within different carbon particle mass concentrations. As observed, the mass change increases with the increase of carbon mass concentration. The vapor generation efficiency increases from $13.2 \%$ to $51.9 \%$ as the carbon particle mass concentration increases from $2.89 \mathrm{~g} \cdot \mathrm{m}^{-2}$ to $10.11 \mathrm{~g} \cdot \mathrm{m}^{-2}$ (Fig. 6b). Higher carbon particle concentration results in a higher optical absorption, which in turn leads to optimum high vapor generation efficiency. It also can be seen that the vapor generation of the PRCMs does not change when the carbon particle concentration is greater than the optimum evaporation concentration $\left(7.22 \mathrm{~g} \cdot \mathrm{m}^{-2}\right)$, which indicates an optimum carbon particle mass can be obtained. The temperature change curve of water increases obviously observed at
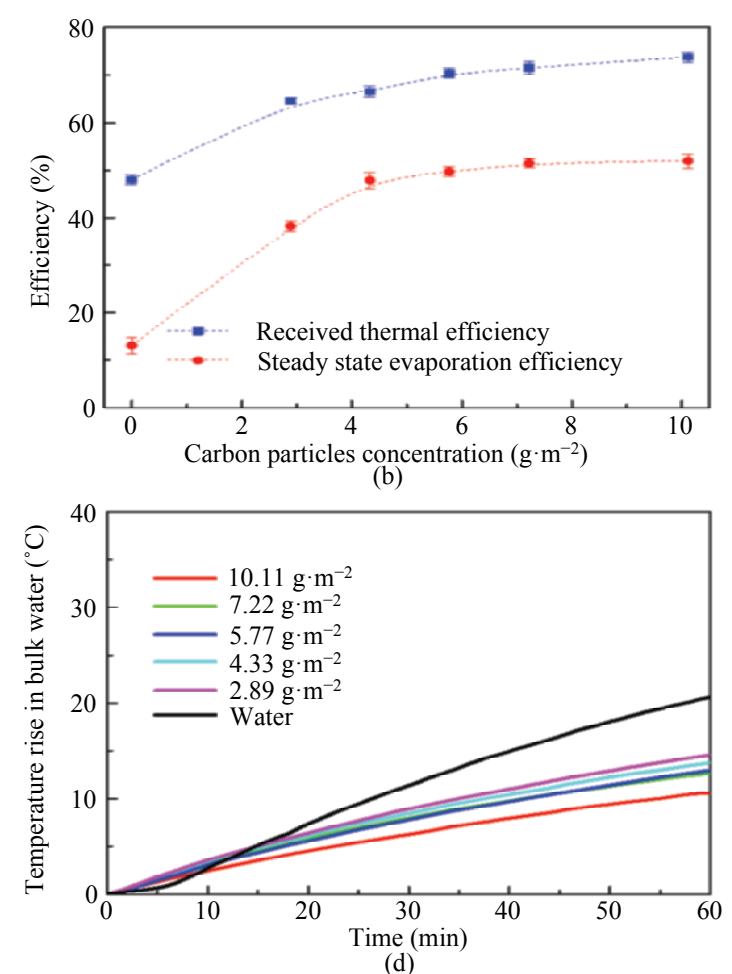

(d)

Fig. 6 Vapor generation of PRCMs with different mass concentrations. (a) Vapor generation mass change; (b) received thermal efficiency and steady state evaporation efficiency; temperature rise of (c) upper area and (d) bulk liquid. 
the top section of the water (Fig. 6c). Several thermocouples exhibit the consistent temperature increases at different depths for pure water, which are significant differences in the temperature increase when the PRCMs are used. The temperature rise curves in the bulk fluid are shown in Fig. 6d. When adding the PRCMs floating on the water, the bulk fluid temperature decreases with the increase of carbon particle mass concentration. It is observed that the highly concentrated carbon particles $\left(7.22 \mathrm{~g} \cdot \mathrm{m}^{-2}\right)$ exhibit the best evaporation efficiency and rate within a relatively low temperature of bulk fluid. As solar light illuminates the PRCMs, it is first absorbed and scattered by the carbon particles and subsequently, a part of it is transferred to the fluid in the lower region. A better solar light absorption at the water-air interface results in localized heating and vapor production. When sunlight irradiates PRCMs, PRCMs are firstly absorbed and scattered by carbon particles, and subsequently, part of them are transferred into the water in deeper area. A better solar absorption at the air-water interface results in heated localization and vapor production.
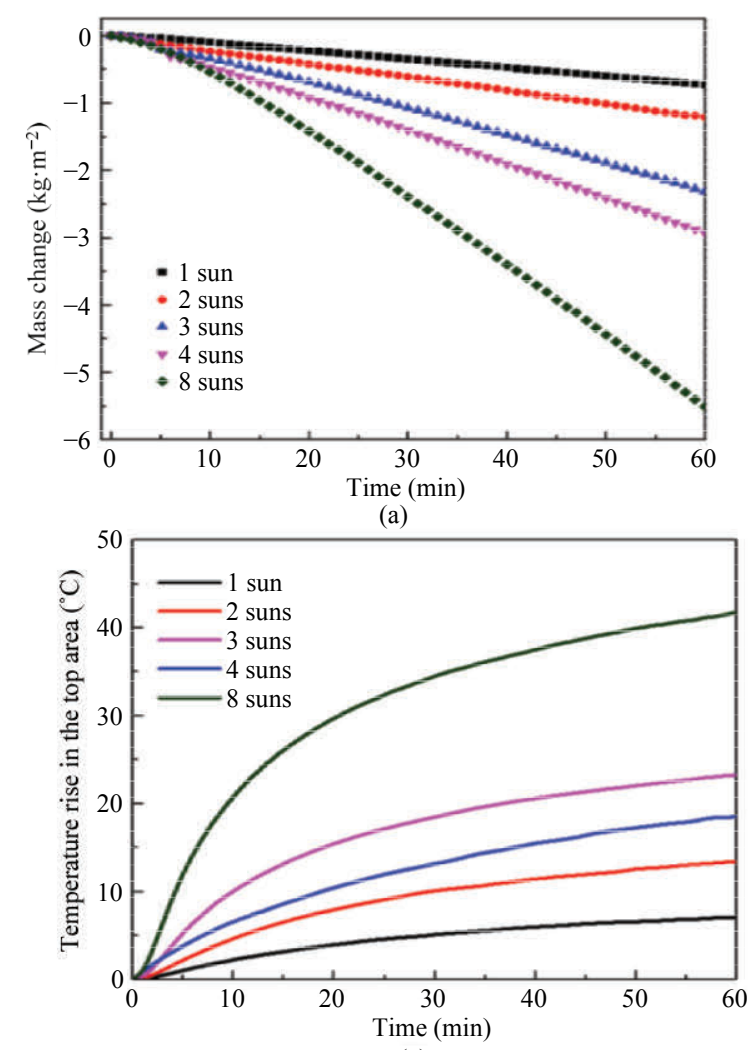

(c)
3.2.2 Effect of solar illumination intensity on vapor generation performance

Fig. 7 shows the vapor generation performance of PRCM $\left(7.22 \mathrm{~g} \cdot \mathrm{m}^{-2}\right)$ and water at different illumination intensities. As depicted in Fig. 7a, the mass change of water increases from $0.588 \mathrm{~kg} \cdot \mathrm{m}^{-2}$ to $2.821 \mathrm{~kg} \cdot \mathrm{m}^{-2}$ with the illumination intensity increases from 1 sun to 8 suns; the PRCM exhibits an important improvement in solar vapor generation. The stable vapor generation flux could be calculated during the last 30 minutes, which is almost linearly related to the time. The thermal receiver efficiency and steady-state evaporation rate as functions of the solar intensity are showed in Fig. 7b. The calculation results show that the evaporation flux of the water increases from $13.2 \%$ to $51.9 \%$ and that this increase is approximately linear with the increase in the illumination intensity. It is evident that steady vapor generation efficiency increases from $42.7 \%$ to $57.7 \%$. From Fig. $7 \mathrm{c}$, the temperature of top-area increases to $7.07{ }^{\circ} \mathrm{C}$ when using 1 sun illumination and reaches a value of $41.9^{\circ} \mathrm{C}$ at 8 suns.

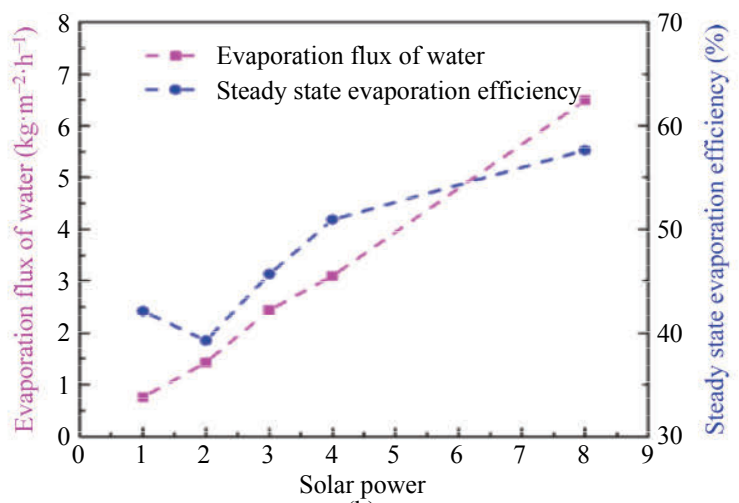

(b)

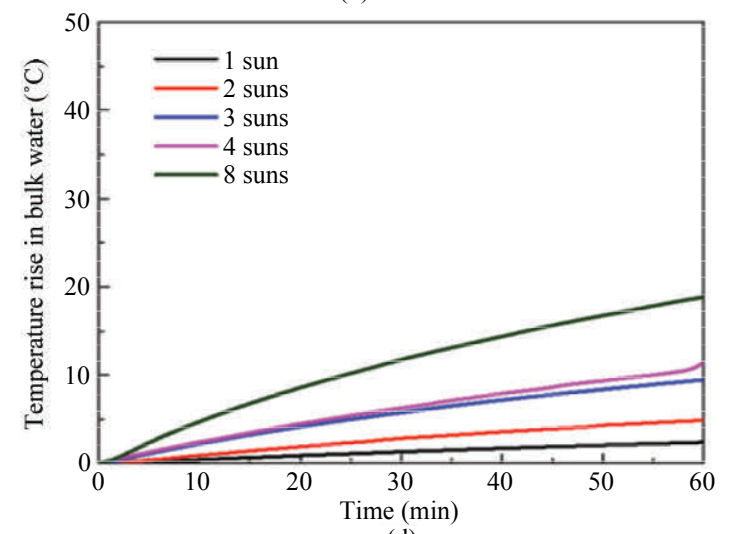

(d)

Fig. 7 Evaporation of the PRCM at different illumination intensities. (a) Mass change of vapor generation; (b) vapor generation flux and steady vapor generation efficiency; the temperature rises at (c) top area and (d) bulk liquid. 

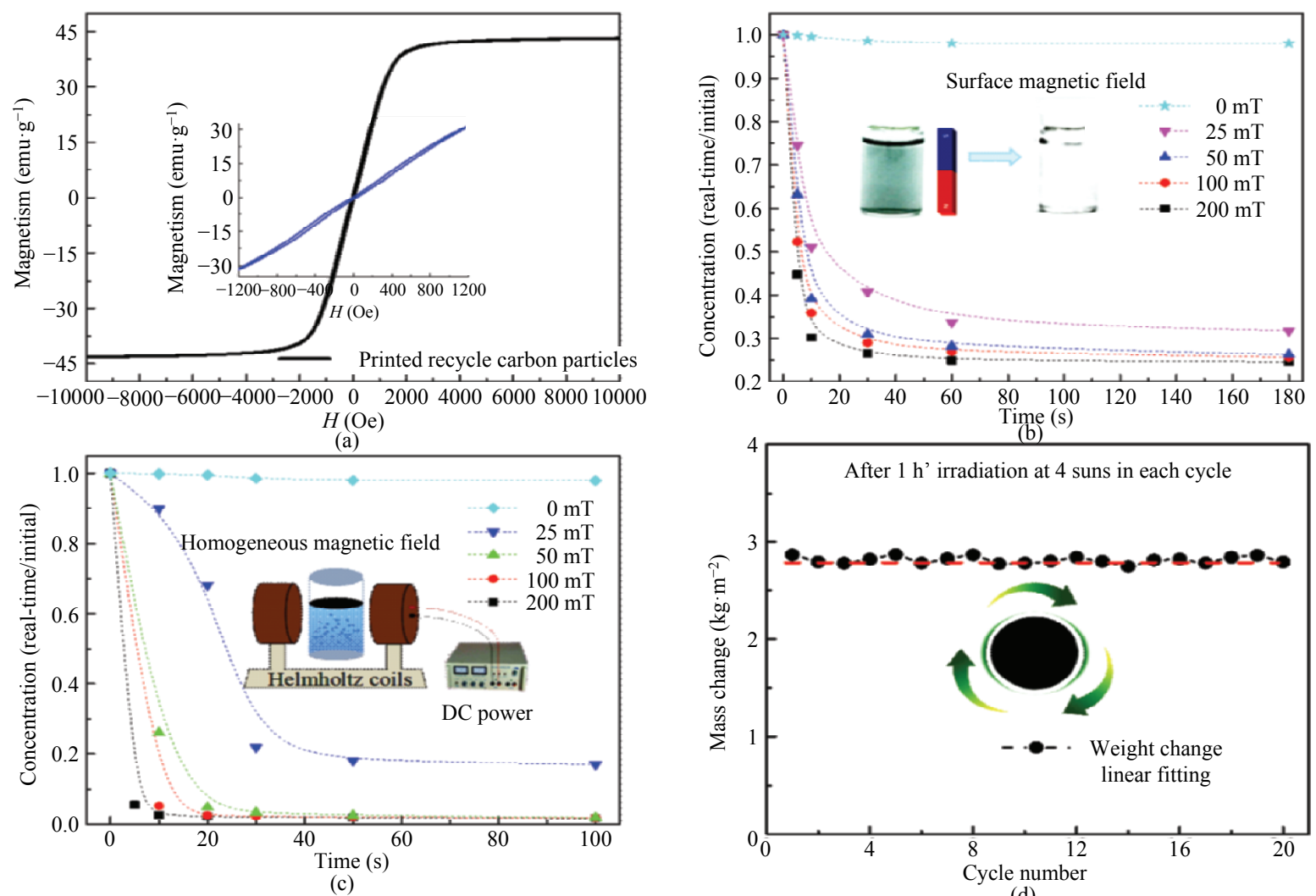

(c)

(d)

Fig. 8 (a) Hysteresis loop of the carbon particles, separation process of carbon particles at (b) surface magnetic field strengths and (c) homogeneous magnetic field, (d) evaporation performance of the PRCM for 20 cycles.

Fig. $7 \mathrm{~d}$ indicates that the bulk temperature of water, which is arithmetic average of all thermocouples increases to $2.4^{\circ} \mathrm{C}$ at 1 sun and is $18.9^{\circ} \mathrm{C}$ at 10 suns. Due to localized heating in the upper section, the temperature gradually decreases from top to bottom along the test beaker.

\subsection{Magnetic separation performance}

The printed carbon particles, which contain magnetic $\mathrm{Fe}_{3} \mathrm{O}_{4}$, could be reused and avoid the pollution caused by the structural damage of the PRCM considering physical friction and chemical corrosion. The hysteresis loops (Fig. 8a) show that some remanence or coercivity exist and the saturation magnetization of the particles is $43.2 \mathrm{emu} \cdot \mathrm{g}^{-1}$. This is probably due to the fact that each $\mathrm{Fe}_{3} \mathrm{O}_{4}$ microsphere is composed of small primary crystals that retain their paramagnetism. According to Beer-Lambert's law, the absorbance of a dilute solution is proportional to the concentration. Based on this principle, we conducted the absorbance test of two dispersants to estimate the concentration changes of dif- ferent suspensions by a comparison with the initial suspension during the separation process ${ }^{[30]}$. Meanwhile, the separation performances under the surface and homogeneous magnetic field were compared with the increasing strength from $25 \mathrm{mT}$ to $200 \mathrm{mT}$ (Figs. $8 \mathrm{~b}$ and $8 \mathrm{c})$. The recovery efficiency of printed carbon particles under surface magnetic field is between $68.2 \%(25 \mathrm{mT})$ and $75.3 \%(200 \mathrm{mT})$, while it ranges from $83.1 \%(25 \mathrm{mT})$ to $99.4 \%$ (200 mT) under homogeneous magnetic field. Under the surface magnetic field, the material recovery efficiency finally reaches saturation after $1 \mathrm{~min}$, which is slower than that of under homogeneous magnetic field. This occurs because the homogeneous magnetic field enables the weaker magnetic particles to receive the magnetic force at a distance and to separate from the water. After the separation process, the PRCM was placed back in the water for evaporation to demonstrate its ability to be recycled (Fig. 8d). And the water production efficiency and cost are demonstrated by desalination experiments. Meanwhile, a comparison of the obtained vapor generation performance with other 
Table 1 Comparison of the evaporation rate, water production efficiency and cost with other works

\begin{tabular}{|c|c|c|c|c|c|}
\hline Evaporation device & $\begin{array}{l}\text { Evaporation rate } \\
\left(\mathrm{kg} \cdot \mathrm{h}^{-1} \cdot \mathrm{m}^{-2}\right)\end{array}$ & $\begin{array}{c}\text { Water production } \\
\text { efficiency }\left(\mathrm{kg} \cdot \mathrm{h}^{-1} \cdot \mathrm{m}^{-2}\right)\end{array}$ & $\begin{array}{l}\text { Water production } \\
\text { cost }\left(\text { yuan } \cdot \mathrm{kg}^{-1}\right)\end{array}$ & Light intensity (sun) & References \\
\hline RGO film & 1.13 & 0.51 & 3.83 & 1 & {$[31]$} \\
\hline Polypyrrole coated cotton fabric & 1.18 & 0.54 & 3.22 & 1 & {$[32]$} \\
\hline Bilayer wood & 0.82 & 0.32 & 4.85 & 1 & {$[33]$} \\
\hline The PRCM & 1.01 & 0.47 & 2.41 & 1 & This work \\
\hline
\end{tabular}

literatures ${ }^{[31-33]}$ has been added by considering evaporation rate, water production efficiency and cost. As can be seen from Table 1, the cost of PRCM is superior to others though neither evaporation rate nor water production efficiency is the best, which is due to the low-cost materials and the rapid printed method.

\section{Conclusion}

In this paper, a low-cost carbon membrane is prepared for solar steam generation inspired by a strategy derived from the plant transpiration. Compared to water, the PRCM exhibits a better optical absorption because of its lower heat transfer and rough surface structure, resulting in higher evaporation efficiency. The evaporation efficiency of water with the PRCM is $52 \%$ under solar illumination intensity of $4 \mathrm{~kW} \cdot \mathrm{m}^{-2}$. Moreover, the PRCM used in this study has a price advantage and is beneficial to industrial production. In addition, the particles that detach from the membrane can be separated from the water and the recovery rate and efficiency of the particle separation can be adjusted by tuning the magnetism intensity. The recovery efficiency of the printed carbon particles reaches $98.4 \%$ at $200 \mathrm{mT}$ under a homogeneous magnetic field. Thus, secondary pollution can be prevented. In future studies, we will commit ourselves to optimize anticorrosion properties of the membrane and thermal insulating properties to further enhance the evaporation efficiency of the system.

\section{Acknowledgment}

This work is financially supported by the China National Key Research and Development Plan Project (2018YFA0702300), the National Natural Science Foundation of China (51676060), and EU ThermaSMART project H2020-MSCA-RISE (778104) Smart thermal management of high power microprocessors using phase-change (ThermaSMART).
Open Access This article is licensed under a Creative Commons Attribution 4.0 International License, which permits use, sharing, adaptation, distribution and reproduction in any medium or format, as long as you give appropriate credit to the original author(s) and the source, provide a link to the Creative Commons licence, and indicate if changes were made.

The images or other third party material in this article are included in the article's Creative Commons licence, unless indicated otherwise in a credit line to the material. If material is not included in the article's Creative Commons licence and your intended use is not permitted by statutory regulation or exceeds the permitted use, you will need to obtain permission directly from the copyright holder.

To view a copy of this licence, visit http://creativecommons.org/licenses/by/4.0/.

\section{References}

[1] Jin H, Lin G, Bai L, Zeiny A, Wen D S. Steam generation in a nanoparticle-based solar receiver. Nano Energy, 2016, 28, 397-406.

[2] Chen X D, Liu Z B, Zheng C Y, Xing F, Yan X Q, Chen Y, Tian J G. High-quality and efficient transfer of large-area graphene films onto different substrates. Carbon, 2013, 56, 271-278.

[3] Wang G, Fu Y, Ma X F, Pi W B, Liu D W, Wang X B. Reusable reduced graphene oxide based double-layer system modified by polyethylenimine for solar steam generation. Carbon, 2017, 114, 117-124.

[4] Wang X Q, Ou G, Wang N, Wu H. Graphene-based recyclable photo-absorbers for high-efficiency seawater desalination. ACS Applied Materials \& Interfaces, 2016, 8, 9194-9199.

[5] Yin Z, Wang H M, Jian M Q, Li Y S, Xia K L, Zhang M C, Wang C Y, Wang Q, Ma M, Zheng Q-S, Zhang Y Y. Extremely black vertically aligned carbon nanotube arrays for solar steam generation. ACS Applied Materials \& Interfaces, 


\section{7, 9, 28596-28603.}

[6] Shi L, Hu Y W, He Y R. Magneto-responsive thermal switch for remote-controlled locomotion and heat transfer based on magnetic nanofluid. Nano Energy, 2020, 71, 104582.

[7] Li H R, He Y R, Liu Z Y, Huang Y M, Jiang B C. Synchronous steam generation and heat collection in a broadband $\mathrm{Ag} @ \mathrm{TiO}_{2}$ core-shell nanoparticle-based receiver. Applied Thermal Engineering, 2017, 121, 617-627.

[8] Shi L, He Y R, Wang X Z, Hu Y W. Recyclable photo-thermal conversion and purification systems via $\mathrm{Fe}_{3} \mathrm{O}_{4} @ \mathrm{TiO}_{2}$ nanoparticles. Energy Conversion and Management, 2018, 171, 272-278.

[9] Guo A K, Ming X, Fu Y, Wang G, Wang X B. Fiber-based, double-sided, reduced graphene oxide films for efficient solar vapor generation. ACS Applied Materials \& Interfaces, 2017, 9, 29958-29964.

[10] Huang H, Shi M H, Ge X S. The effect of a black insulation sheet on the evaporation rate from a shallow salt pond. International Journal of Energy Research, 1999, 23, 31-39.

[11] Taylor R A, Phelan P E, Otanicar T P, Walker C A, Nguyen $\mathrm{M}$, Trimble S, Prasher R. Applicability of nanofluids in high flux solar collectors. Journal of Renewable and Sustainable Energy, 2011, 3, 023104.

[12] Zeng Y, Yao J F, Horri B A, Wang K, Wu Y Z, Li D, Wang H T. Solar evaporation enhancement using floating light-absorbing magnetic particles. Energy \& Environmental Science, 2011, 4, 4074-4078.

[13] Ghasemi H, Ni G, Marconnet A M, Loomis J, Yerci S, Miljkovic N, Chen G. Solar steam generation by heat localization. Nature Communications, 2014, 5, 4449.

[14] Chang C, Yang C, Liu Y M, Tao P, Song C Y, Shang W, Wu J $\mathrm{B}$, Deng T. Efficient solar-thermal energy harvest driven by interfacial plasmonic heating-assisted evaporation. ACS Applied Materials \& Interfaces, 2016, 8, 23412-23418.

[15] Lenert A, Wang E N. Optimization of nanofluid volumetric receivers for solar thermal energy conversion. Solar Energy, 2012, 86, 253-265.

[16] Liu Y M, Yu S T, Feng R, Bernard A, Liu Y, Zhang Y, Duan H Z, Shang W, Tao P, Song C Y, Deng T. A bioinspired, reusable, paper-based system for high-performance large-scale evaporation. Advanced Materials, 2015, 27, 2768-2774.

[17] Hurt R H, Monthioux M, Kane A. Toxicology of carbon nanomaterials: status, trends, and perspectives on the special issue. Carbon, 2006, 44, 1028-1033.

[18] Ni G, Miljkovic N, Ghasemi H, Huang X, Boriskina S V, Lin C T, Wang J, Xu Y, Rahman M M, Zhang T, Chen G.
Volumetric solar heating of nanofluids for direct vapor generation. Nano Energy, 2015, 17, 290-301.

[19] Shi L, Hu Y W, Bai Y J, He Y R. Dynamic tuning of magnetic phase change composites for solar-thermal conversion and energy storage. Applied Energy, 2020, 263, 114570.

[20] Shi L, He Y R, Huang Y, Jiang B C. Recyclable $\mathrm{Fe}_{3} \mathrm{O}_{4} @ \mathrm{CNT}$ nanoparticles for high-efficiency solar vapor generation. Energy Conversion and Management, 2017, 149, 401-408.

[21] Zhou L, Tan Y L, Ji D X, Zhu B, Zhang P, Xu J, Gan Q Q, Yu Z F, Zhu J. Self-assembly of highly efficient, broadband plasmonic absorbers for solar steam generation. Science Advances, 2016, 2, e1501227.

[22] Wang Z H, Liu Y M, Tao P, Shen Q C, Yi N, Zhang F Y, Liu Q L, Song C Y, Zhang D, Shang W, Deng T. Bio-inspired evaporation through plasmonic film of nanoparticles at the air-water interface. Small, 2014, 10, 3234-3239.

[23] Wheeler T D, Stroock A D. The transpiration of water at negative pressures in a synthetic tree. Nature, 2008, 455, 208-212.

[24] Li B, Yan Y Y. Solid desiccant dehumidification techniques inspired from natural electroosmosis phenomena. Journal of Bionic Engineering, 2011, 8, 90-97.

[25] Gao H C, Xiao F, Ching C B, Duan H W. One-step electrochemical synthesis of PtNi nanoparticle-graphene nanocomposites for nonenzymatic amperometric glucose detection. ACS Applied Materials and Interfaces, 2011, 3, 3049-3057.

[26] Yao Y R, Huang W Z, Zhou H, Zheng Y F, Song X C. Self-assembly of dandelion-like $\mathrm{Fe}_{3} \mathrm{O}_{4} @ \mathrm{C} @ \mathrm{BiOCl}$ magnetic nanocomposites with excellent solar-driven photocatalytic properties. Journal of Nanoparticle Research, 2014, 16, 2451.

[27] Hong J J, Liu S, Glover P, Wu S Y, Yan Y Y. Mathematical and experimental investigation of water migration in plant xylem. Journal of Bionic Engineering, 2017, 14, 622-630.

[28] Wang Q, Hong J J, Yan Y Y. Biomimetic capillary inspired heat pipe wicks. Journal of Bionic Engineering, 2014, 11, 469-480.

[29] Gao M X, Deng C H, Fan Z Q, Yao N, Xu X Q, Yang P Y, Zhang X M. A simple pathway to the synthesis of magnetic nanoparticles with immobilized metal ions for the fast removal of microcystins in water. Small, 2007, 3, 1714-1717.

[30] Swinehart D F. The beer-lambert law. Journal of Chemical Education, 1962, 39, 333.

[31] Guo A K, Ming X, Fu Y, Wang G, Wang X B. Fiber-based, double-sided, reduced graphene oxide films for efficient 
solar vapor generation. ACS Applied Materials \& Interfaces, 2017, 9, 29958-29964.

[32] Hao D D, Yang Y D, Xu B, Cai Z S. Efficient solar water vapor generation enabled by water-absorbing polypyrrole coated cotton fabric with enhanced heat localization. Applied Thermal Engineering, 2018, 141, 406-412.
[33] Zhu M W, Li Y J, Chen G, Jiang F, Yang Z, Luo X G, Wang Y B, Lacey S D, Dai J Q, Wang C W, Jia Chao, Wan J Y, Yao Y G, Gong A, Yang B, Yu Z F, Das S, Hu L B. Tree-inspired design for high-efficiency water extraction. Advanced Materials, 2017, 29, 1704107. 